\title{
Systemic Impact Caused by the Integration of La Guajira Wind Farm
}

\author{
Francisco M. Gonzalez-Longatt \\ School of Electrical, Electronic and System Engineering \\ Loughborough University \\ Loughborough, United Kingdom \\ fglongatt@fglongatt.org
}

\begin{abstract}
La Guajira Peninsula on the western part of Venezuela has been defined as a potential area for wind power developments and one of them is La Guajira wind farm. This paper establishes the systemic impact of the integration of the Phase 1 of this wind farm on the western area of Venezuelan power system. Three integration scenarios are defined in this paper considering the connection of transmission lines on either $138 \mathrm{kV}$ or $24 \mathrm{kV}$. The steady-state performance is evaluated considering the changes on the local voltage profile. The dynamic behavior of the western Zulia power system is evaluated trough response of the main electro-mechanical variables obtained from time-domain simulations. Two large contingencies are considered. The main contribution of this paper is demonstrates the positive effect of the wind farm integration on $138 \mathrm{kV}$, the low voltage fault through capabilities on the wind turbine enables good voltage profile during fault condition and fast post contingency voltage recovery.
\end{abstract}

Keywords-Electric power system, power system dynamic, wind power generation, wind power integration

\section{INTRODUCTION}

A long history of history related the interest of Bolivarian Republic of Venezuela on developing Renewable Energy Sources (RES) is found in some reports since 60's [1]. However, more aggressive policies on the use of environmentally friendly electricity generation have begun in recent years. Several academic projects have been reported to promote RES installations in several areas of Venezuela [2], [3]-[4], especially wind power energy. It includes five proposed wind farms: the archipelagoes and islands of Los Roques, Los Monjes, La Ochila, La Blanquilla and La Tortuga Island [2]. In addition to these projects, two wind farms, of utility scale, are presently under development in mainland Venezuela: La Guajira, and La Peninsula de Paraguaná [1], [2], [3].

There is not a Venezuelan wind atlas currently available for Venezuela, however, some reports [4], [3] has identified some preliminary areas suitable for wind energy projects and includes La Guajira peninsula [2], [5]. The Venezuelan government has defined a preliminary plan to use the wind energy resource available in Venezuela in recent time; it is named in Spanish: "Plan Piloto Nacional de Generación Eólica" (National Plan for the use of wind power). This ambitious plan was defined to start on 2008 until 2013 and it included installation of twenty weather stations across several locations across Venezuela. Three locations were defined in La Guajira peninsula and meteorological towers equipped with anemometers, wind vanes, temperature, pressure, and relative humidity sensors were selected to be installed at: (i) Caño Paijana (Lat. 11.132222, Long. -71.805833), (ii) Caño Sagua (11.3765, -71.956), (iii) Quisiro (10.9000, -71.31666). The average-monthly wind speed for the Caño Sagua, and Caño Paijara are shown on Fig. 1, where a yearly-average is $8.85 \mathrm{~m} / \mathrm{s}$ and $8.09 \mathrm{~m} / \mathrm{s}$ respectively.

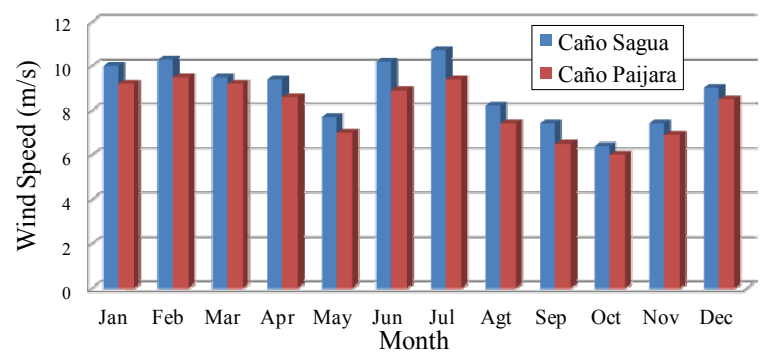

Fig. 1. Monthly Wind Speed at two locations on the La Guajira Peninsula.

H. Montiel in [5] defined La Guajira peninsula wind potential is of a "world class quality" based on measurements plus satellite measurements and references meteorological stations. The author claims the possibility of installing more than 10,000 MW on five stages considering onshore and offshore wind farms in the Gulf of Venezuela. The objective of this paper is to establish the systemic impact of the integration of the Phase 1 of this wind farm on the western area of Venezuelan power system. All the data used for simulations purposes is publically available.

The structure of this paper is a follow. Section II describes briefly the western Zulia power system, La Guajira wind farm, defines the wind turbines model used in this paper and define the integration cases whilst Section III presents the simulation results and discussion about the finding with special emphasis on their significance on the systemic impact. The main contribution of this paper is demonstrates the positive effect of the wind farm integration on $138 \mathrm{kV}$, the low voltage fault through capabilities on the wind turbine enables good voltage profile during fault condition and fast post contingency voltage 
recovery. The conclusions of this paper are presented on Section IV.

\section{SYSTEM DESCRIPTION AND MODELING}

\section{A. Wind Power Projects at La Guajira Peninsula}

H. Montiel in his paper titled "Pilot Project for La Guajira Wind Plant" [5] proposes the development of the wind power at La Guajira Peninsula. Five stages are defined: four are located on land and a fifth stage that involves offshore wind power (see Fig. 2). The final stage suggests the possibility of installing more than $10,000 \mathrm{MW}$ in the Gulf of Venezuela.

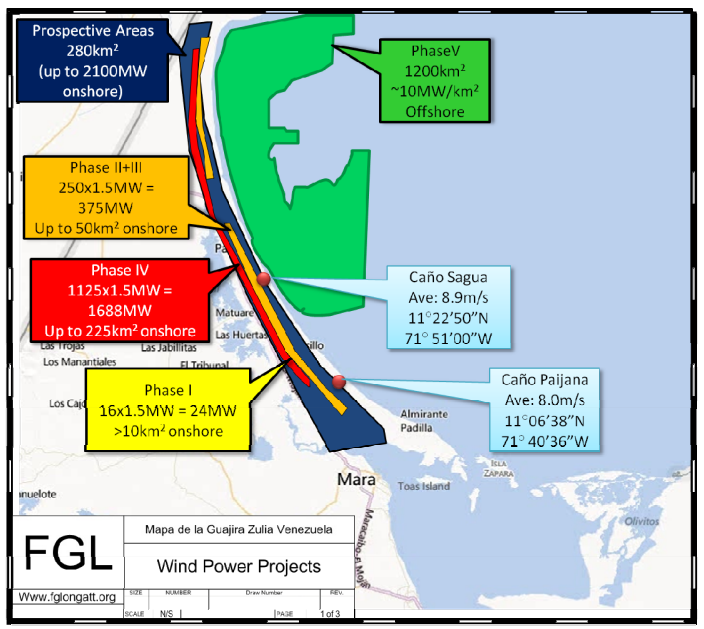

Fig. 2. General description of the five stages proposed for the developing of wind power at La Guajira Peninsula.

The final target of the Venezuelan Government is to develop 10,000 MW in the area of the Upper Guajira from Caño Sagua and Caño Paijana [6]. La Guajira wind farm is one of the potential projects in this area. This project is to be developed in six stages made up of 36 wind turbines. A surface area of $285 \mathrm{~km}^{2}$ will be used to install 216 wind turbines generating $454 \mathrm{MW}$.

The Phase 1 of the La Guajira wind farm consists of 75.6 MW and it will be developed in two phases: (i) Phase 1- $A$ that involves the installation of 12 wind turbines of $2.1 \mathrm{MW}$ each one (25.2 MW) and (ii) Phase 1-B will generate 50.4 MW. This stage is designed to supply power to the municipalities of Mara, Guajira and Almirante Padilla. The Argentinean Company IMPSA Wind provides the wind turbines for the Stage 1 of La Guajira wind farm in Venezuela. Four IWP-832100 wind turbines have been already erected on the windfarm using tower of 72-meters. The Phase 1-B will see Guajira expanded in six mini-tranches to a total of $75.6 \mathrm{MW}$ with 36 turbines installed and operational by 2014 . The IWP-83-2100 is a variable speed wind turbine (VSWT) developed by UNIPOWER and uses the direct-drive concept. This wind turbine provides a nominal power of $2.1 \mathrm{MW}$ at nominal wind speed of $13 \mathrm{~m} / \mathrm{s}$ and is designed considering a wind class IIIEC- 61400-1. It uses a multi-pole permanent magnet synchronous generator (PMSG) is connected to the grid using a full power converter (FPC).

\section{B. Western Zulia Power System}

Venezuela's power system is an integrated vertical power company, called Corporación Electrica Nacional (Corpoelec) which covers most of the country, and it includes electricity grid consists of 11,747 kilometers of $765 \mathrm{kV}, 400 \mathrm{kV}$, and 230 $\mathrm{kV}$ transmission lines. One of the operational areas on the Venezuela's power covers the western part of Venezuela and is known ad Western Zulia. The peak of power demand in this power system is $1,713 \mathrm{MW}$ and 13 generation units produces around 1,105 MW, the remaining demand is supplied by interconnection to the Venezuela's power system. The western Zulia power system includes 116 transmission lines in 230, 138 and 137 buses operating at $24 \mathrm{kV}$. A simplified representation of the most important components involved on the integration of La Guajira wind farm is depicted on Fig 3.

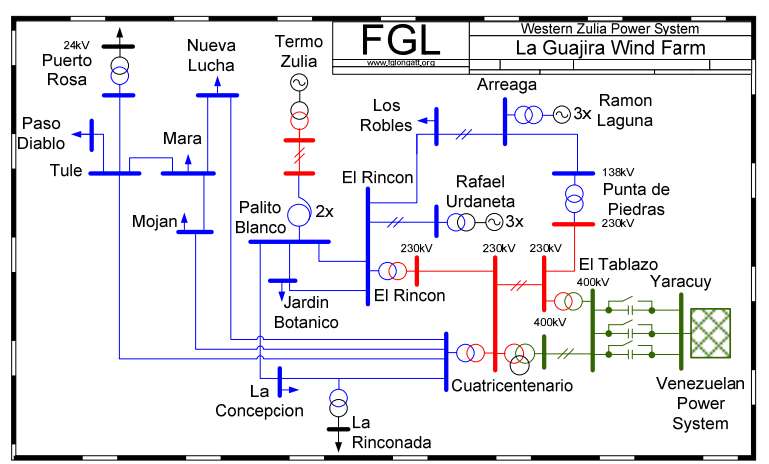

Fig. 3. Representative single-line diagram of the Western Zulia Power System.

\section{Wind Turbine Modeling}

Fig. 4 depicts the general structure of the full model for a VSWT with a direct-drive PMSG connected to the grid using a full converter. The main subsystems shown on Fig. 4 are modeled in this paper. Models and parameters are carefully selected from previous publications [7], [8], [9], [10].

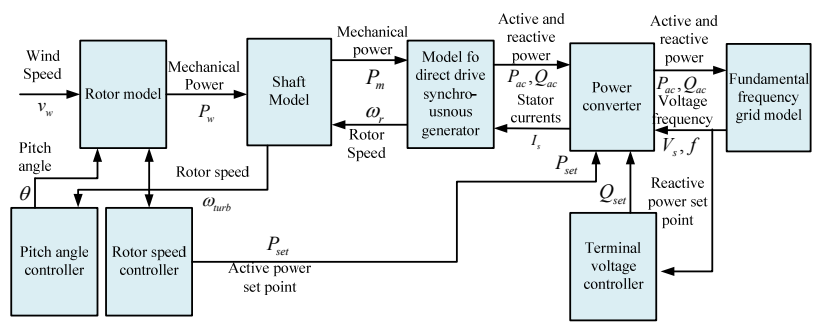

Fig. 4. General structure for the model of a VSWT with a direct-drive PMSG [9]. [11].

\section{Integration Scenarios}

Three cases are defined in this paper for connection of $\mathrm{La}$ Guajira wind farm: Case I: The Phase 1-A (25.2 MW) assumed to be connected to the Western Zulia power system using two transmission lines $(24 \mathrm{kV})$ from the Cataneja substation. Case II: The Phase 1 of La Guajira wind farm (75.6 MW) is connected by two transmission lines at $24 \mathrm{kV}$ to the Puerto Rosa substation. Case III: The Phase 1 (75.6 MW) is connected to the Puerto Rosa substation using two transmission lines at 
$138 \mathrm{kV}$. Two overhead transmission lines are considered in each case in order to provide flexibility on normal operation and increases security. Conductor type AAC Petunia $750 \mathrm{kcmil}$ 37 is used on the transmission line design.

\section{Simulations AND Results}

The integration of La Guajira wind farm into the Western Zulia power system is expected to produce changes on the system's performance. The assessment of these changes is necessary to define some potential system reinforcements. This section presents the main simulations and results analyses about the integration scenarios defined on Section II-D. Steadystate and time-domain $(60 \mathrm{sec})$ simulations are performed using DIgSILENT $^{\circledR}$ PowerFactory $^{\text {TM }}$ [12]. Dynamic models are created by the author using DIgSILENT Simulation Language (DSL).

\section{A. Changes of Voltage Profile}

Steady-state bus voltages of all integration scenarios are calculated using power flows. Full converter wind turbine allows voltage or power factor control. Four constant power factors $(p f)$ are considered in each case: $1.0,0.99,0.98$ and 0.97 (producing reactive power). The bus voltage change $(\Delta V)$ is calculated in percentage $(\%)$ of the deviation from the voltage previous the integration of La Guajira wind farm. Fig. 5 shows the voltage change in the most important and representative substations on Western Zulia power system. Lower power factor produces large changes on the bus voltages. Considering the integration Case I, it has a very positive effect on the local voltage profile. In fact, there are not over-voltages. Case II and Case III produce the largest voltage rising even considering the wind farm working at unitary power factor. It must be noticed, Case II and Case III operation a power factor lower than 0.99 capacitive produces excessive local voltage elevation and the Case III is suggested to be operated at unitary power factor for all production regimes. It must notice Case I (25.2 MW) provided a lower power injection than Case II and III (75.6 MW). The increases on the bus voltages for the substations with short electrical distance from the wind farm are significantly higher that remote substations. There is a significant improvement on the bus voltage at Puerto Rosa, Paso Diablo, Mara and Tule substations. The integration of La Guajira wind farm using transmission system at $138 \mathrm{kV}$, Case $I I I$, provides the best results in term of local steady-state voltages.

\section{B. Dynamic Behavior}

A three-phase short circuit on overhead transmission line followed by circuit breakers opening the faulted transmission line is selected as event of evaluate the local dynamic on the western Zulia power system. Two well-known large disturbances on $230 \mathrm{kV}$ transmission lines are used for dynamic simulations in this paper: 1) Tablazo-Punta Palma $230 \mathrm{kV}$ and 2) Tablazo-Cuatricentenario $400 \mathrm{kV}$. Time-domain simulations during $60 \mathrm{sec}$ are performed. Simulation results are presented in the form of plots for variables corresponding to the system $\left(V, P, Q\right.$ and $\left.\omega_{r}\right)$ and wind farm $\left(V, P, Q\right.$ and $\left.V_{d c}\right)$ side. Results for integration Case $I$ and Case III are presented in this paper and comments and analysis for key finding are presented. Results of Case II are not presented in this paper because space limitations.
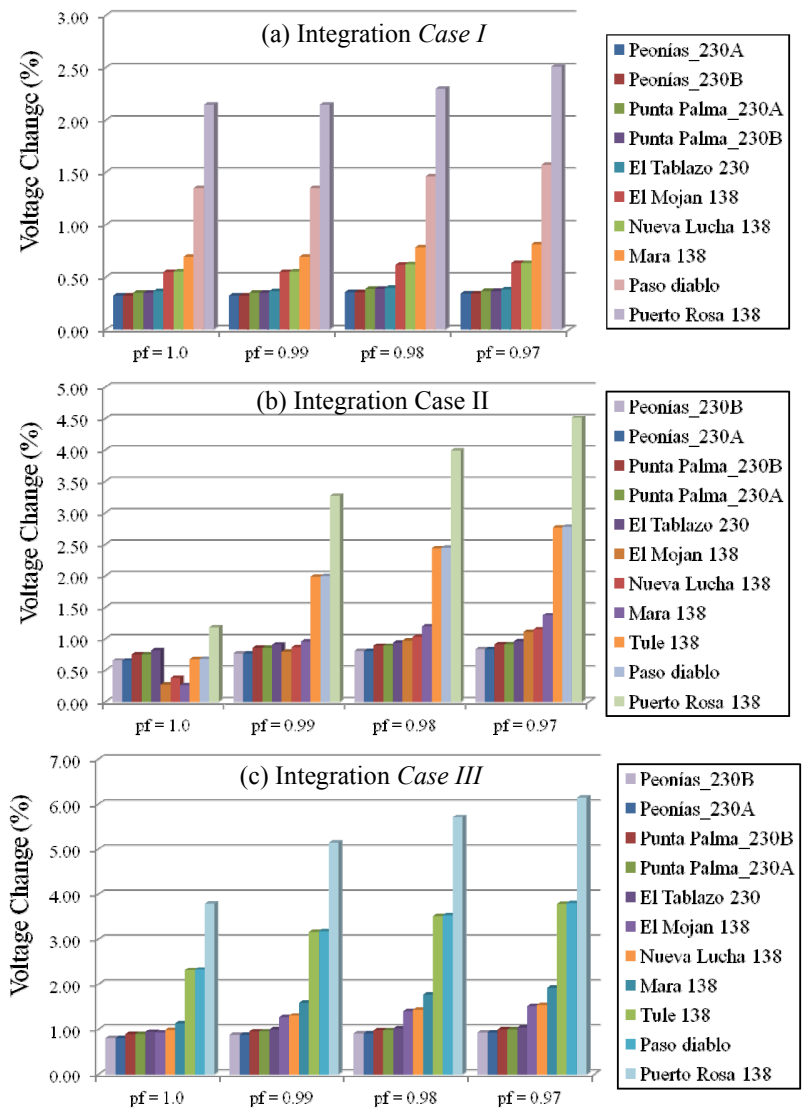

Fig. 5. Changes on Steady-State bus Voltages for the Integration Cases.

\section{Contingency A: Tablazo-Punta Palma $230 \mathrm{kV}$}

This contingency produce a large impact on the local dynamic, it involves the loss of $115 \mathrm{MW}$ power transfer on the Base Case and very low voltages post disturbance (Ave. $<0.76$ p.u) with slow post disturbance recovery $(\sim 1.65 \mathrm{sec})$. The generation unit RLG_16 in Ramon Laguna power plant exhibits the largest changes on electro-mechanical variables. In this contingency, the large clearing times (>590 msec) trips create voltages oscillations and produce local voltage stability problems (see Fig. 6). The trip of Tablazo-Punta Palma transmission line creates a deficit of reactive power around 52MVAr. Fig. 7 shows the results considering the integration Case I and $527 \mathrm{msec}$ clearing time. The wind turbines used on the wind farm includes low voltage fault through (LVFT) capability allowing a better voltage profile during the fault on the substations near to the wind farm, and a slightly faster recovery period. However, the reactive power production on Case $I$ is not enough to produce dramatic systemic improvements. Fig. 8 shows the results for integration Case II. The improvements on bus voltages during and after faults are notorious as consequence of the transient reactive power control on the wind turbines. Rotor speed deviations on all local generation units are reduced. Also the systemic reactive power production during and after the fault are reduced. 


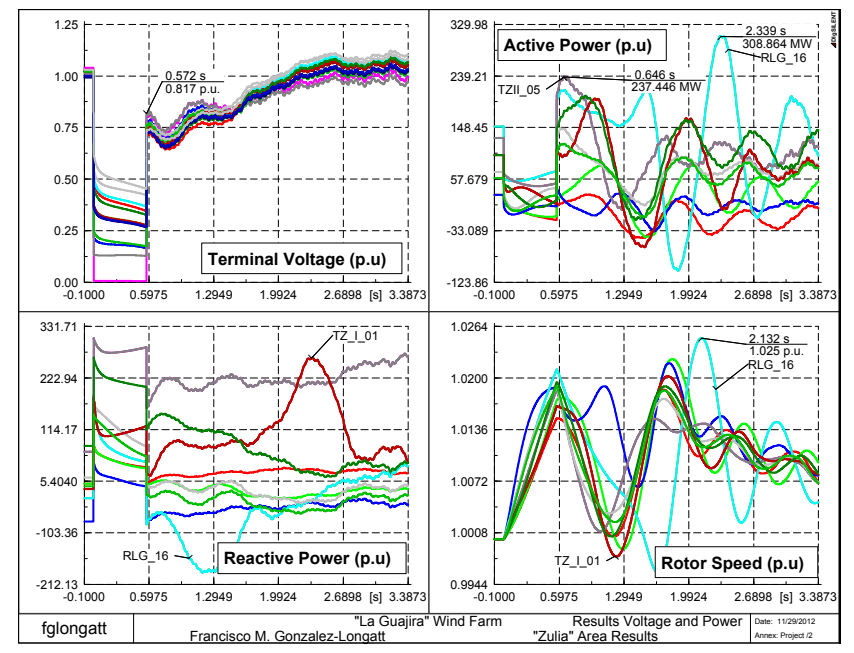

Fig. 6. Response of Western Zulia power System: Contingency A, Base Case.

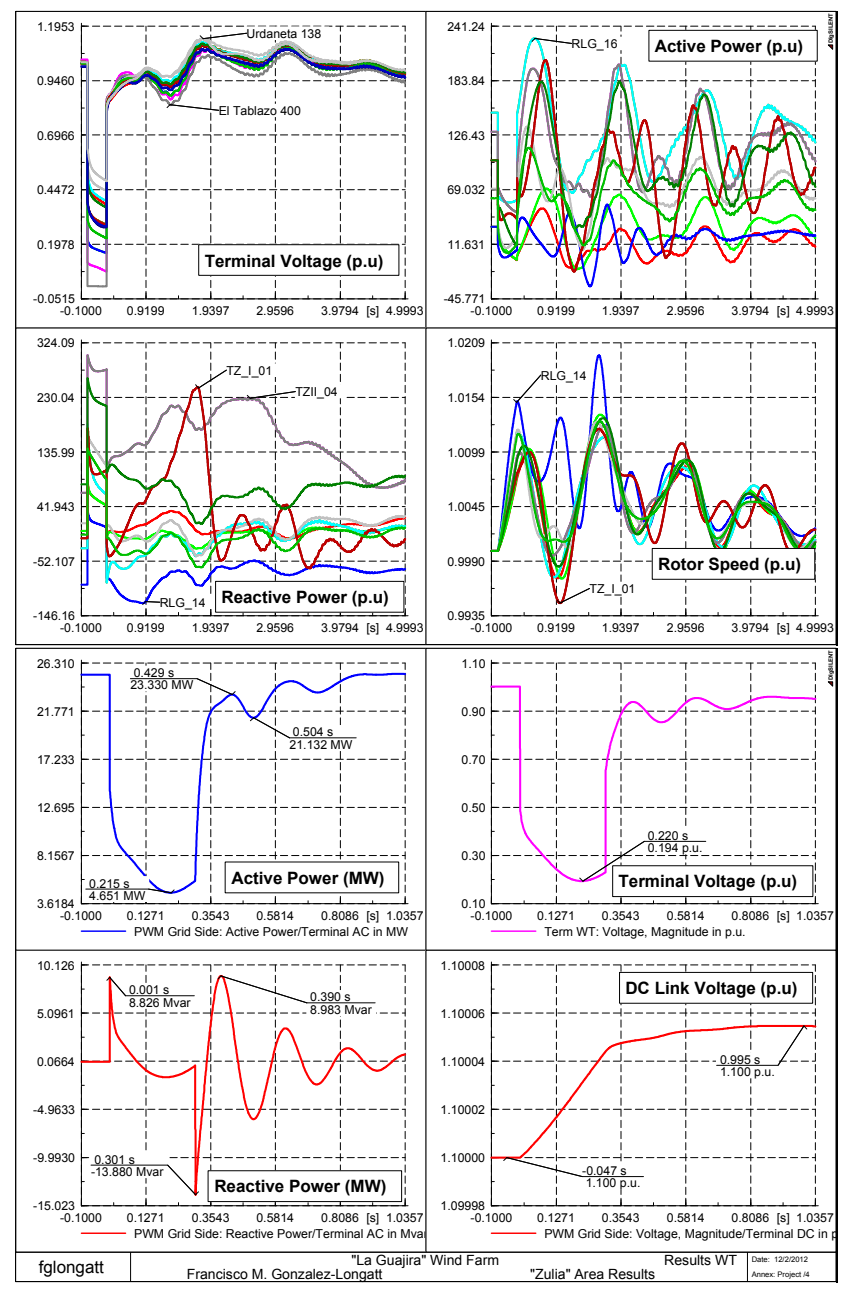

Fig. 7. Response of Western Zulia power System: Contingency A, Case I.

The unit TZ_I_01, Termo Zulia power plant, is no longer the generation unit that produces the maximum instantaneous reactive power values during the systemic voltage recovery period.

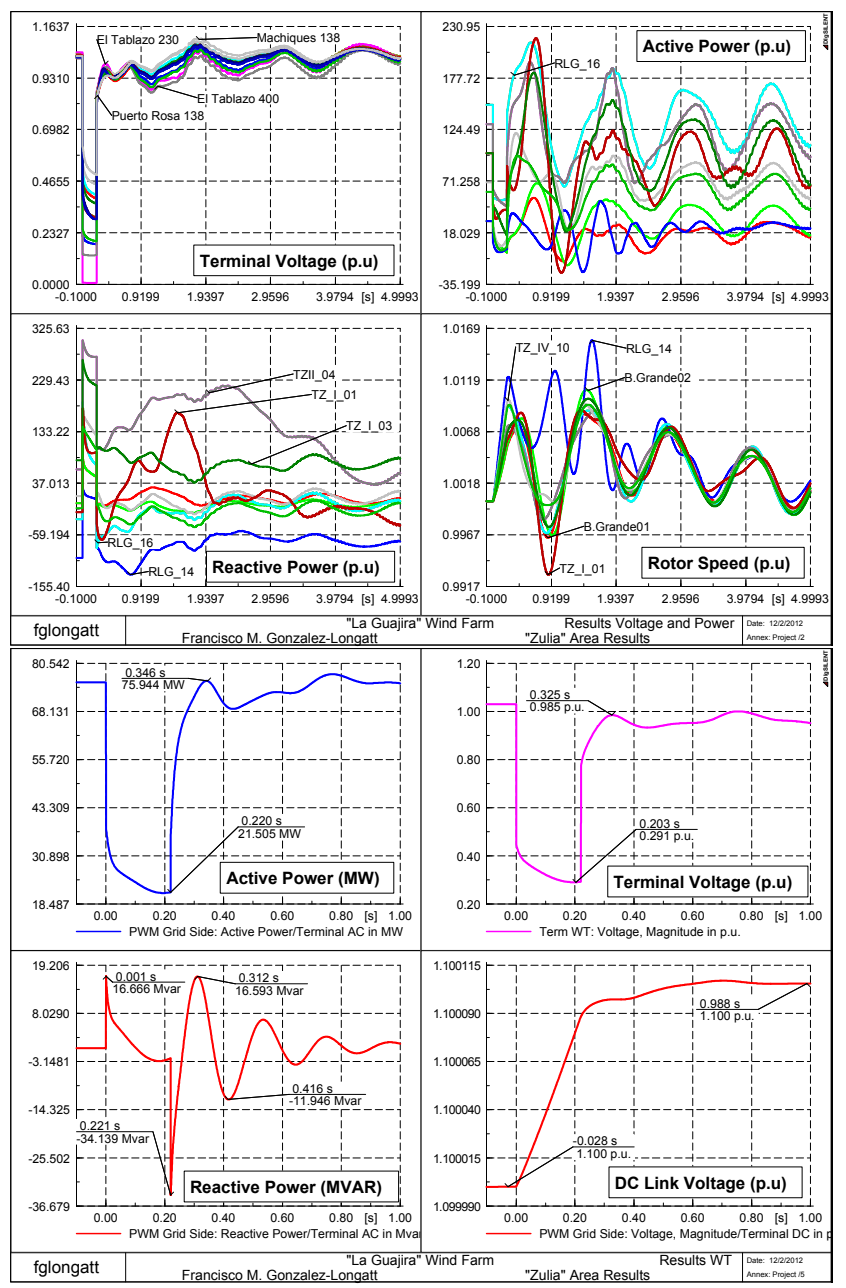

Fig. 8. Response of Western Zulia power System: Contingency A, Case II.

\section{Contingency B:Tablazo-Cuatricentenario $400 \mathrm{kV}$}

Tablazo-Cuatricentenario transmission line allows a power flow feeding from the Venezuela's power system $(\sim 145 \mathrm{MW}$, 48 MVar). A contingency in this transmission line creates a serious generation deficit, problems of voltage and angle stability are possible for long clearing times $(>295 \mathrm{msec})$. Fig. 9 shows the results for this contingency on the base case. The extreme values on the active power and rotor speed on the generation units are larger in this contingency compared with the Contingency $A$. It demonstrated the severity of the contingency and the potential security risk. Fig. 10 shows the simulations results considering the integration Case II. The power flows produced by the wind farm during this event are highly controllable with very small time constant. This response provides very positive systemic consequences, good post distance voltages (Ave. $>0.78$ p.u) and fast recovery voltage response $(<0.98 \mathrm{sec})$. 


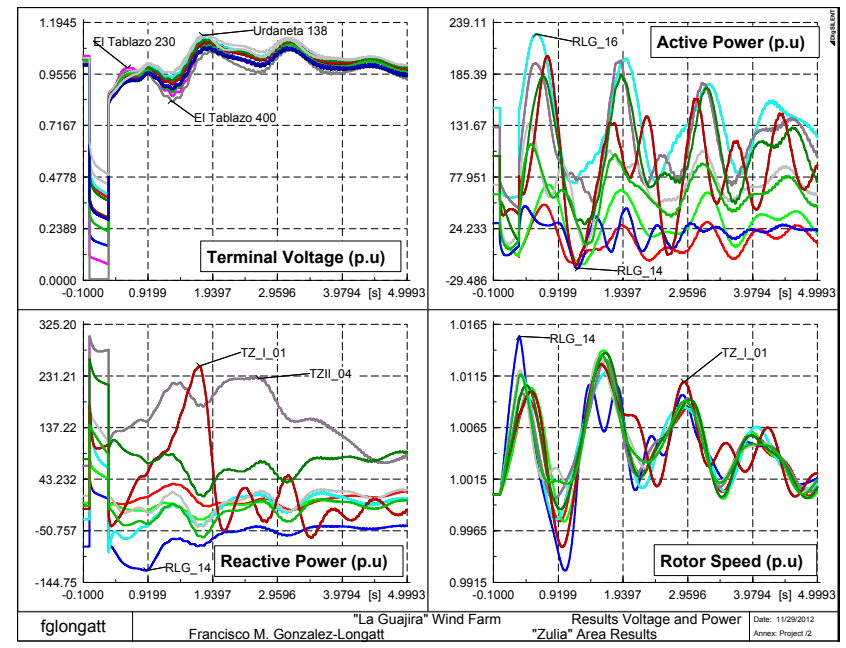

Fig. 9. Response of Western Zulia power System: Contingency B, Base Case.

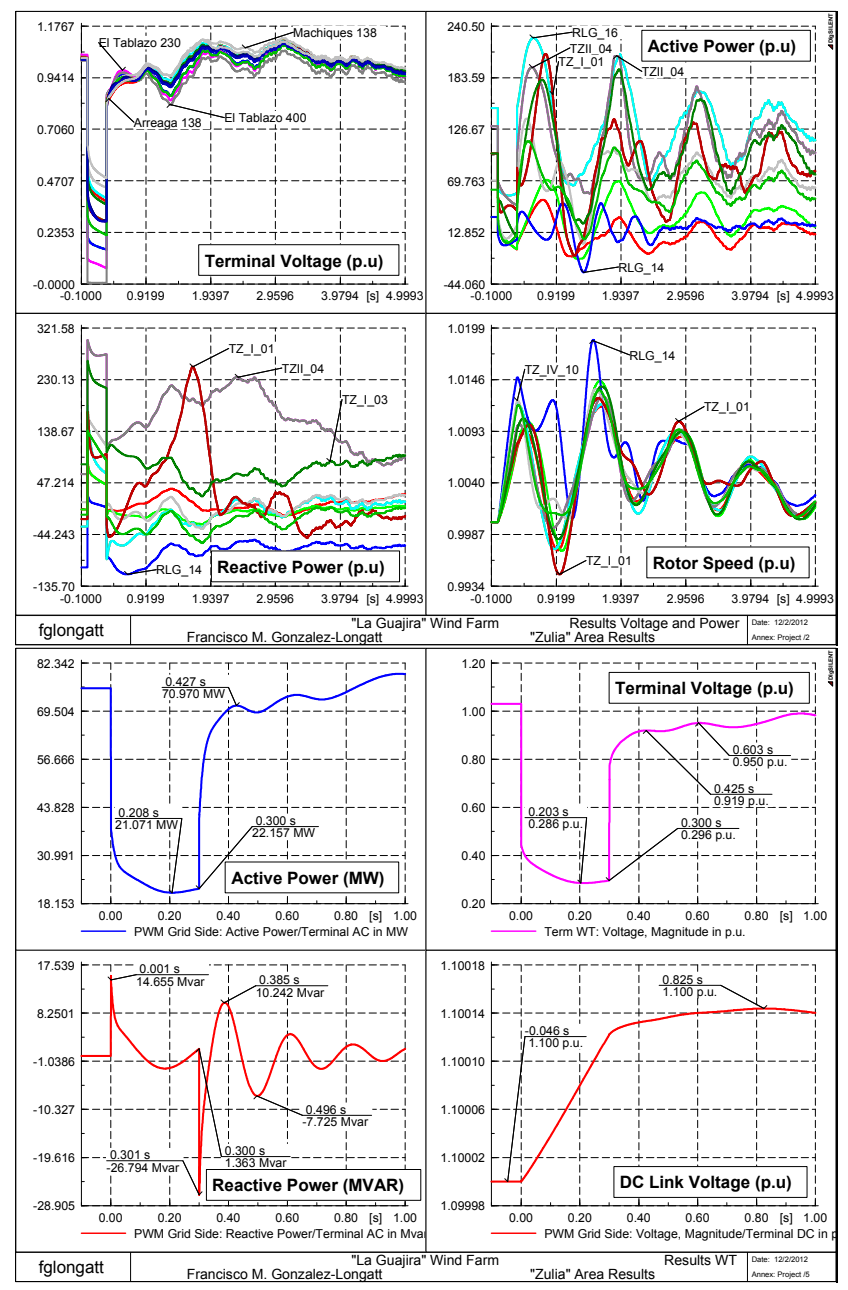

Fig. 10. Response of Western Zulia power System: Contingency B, Case II.

During the fault condition the wind farm stay connected and injecting active power to the western Zulia power system, it has a very positive impact on the transient stability. The rotor speed exclusions during the first swing are reduced and the maximum rotor speed exclusion is delayed several hundred milliseconds.

\section{CONCLUSION}

The simulation results of the systemic impact produced by the integration of the Phase 1 of La Guajira wind farm on the western area of Venezuelan power system are presented in this paper. Three integration cases of the integration are considered based on the use of transmission lines connected to the western Zulia power system, either on $138 \mathrm{kV}$ or $24 \mathrm{kV}$. Simulations results demonstrate the positive systemic impact of the integration of La Guajira wind farm (75.6 MW) using two transmission lines at $138 \mathrm{kV}$. This interconnection provides the best performance in term of local steady-state voltages, good post fault voltage profile and fast recovery voltage response.

\section{REFERENCES}

[1] G. Massabie, Venezuela: A Petro-State Using Renewable Energies - A Contribution to the Global Debate about New Renewable Energies for Electricity Generation: VS Verlag für Sozialwissenschaften, 2008.

[2] F. González-Longatt, J. Méndez, R. Villasana, and C. Peraza, "Wind Energy Resource Evaluation on Venezuela: Part I," Nordic Wind Power Conference NWPC 2006, Espoo, Finland, 2006.

[3] F. González-Longatt, J. Méndez, and R. Villasana, "Preliminary Evaluation of Wind Energy Utilization on Margarita Island, Venezuela," Sixth International Workshop on large-Scale of Integration of Wind Power and Transmission Networks for Offshore Wind Farms, Delft, Netherlands, 2006.

[4] M. Acosta, "Impacto de la Compensacion Reactiva en el Comportamiento de la Generacion Eolica. Caso de Estudio: Isla de Margarita," Especialista en Instalaciones Eléctricas, Departamento de Conversion y Transporte, Universidad Simon Bolivar, Caracas, Venezuela, 2005.

[5] H. Montiel, "Pilot Project for "La Guajira" Wind Plant," IEEE Transmission \& Distribution Conference and Exposition: Latin America, 2006. TDC '06. IEEE/PES, 2006, pp. 1-4.

[6] GotPowered.com. (2012, 27 November). Wind in Venezuela: Wind Farm in La Guajira. Available: http://gotpowered.com/2012/wind-invenezuela-wind-farm-in-la-guajira/

[7] T. Ackermann, Wind power in power systems. Chichester: John Wiley \& Sons, 2005.

[8] J. G. Slootweg, "Wind Power. Modeling and Impact on Power System Dynamics," PhD Thesis, Faculty Electrical Engineering, Mathematics and Computer Science, University of Delft, Delft, Netherlands, 2003.

[9] F. González-Longatt, P. Wall, and V. Terzija, "A Simplified Model for Dynamic Behavior of Permanent Magnet Synchronous Generator for Direct Drive Wind Turbines," IEEE PES Trondheim PowerTech 2011, Trondheim, Norway, 2011.

[10] S. Achilles and M. Poller. Direct drive synchronous machine models for stability assessment of wind farm. Available: http://www.digsilent.de/Consulting/Publications/DirectDrive_Modeling. pdf

[11] F. Gonzalez-Longatt, "Dynamical Model of Variable Speed WECS: Attend of Simplification," Fifth International Workshop on Large Scale Integration of Wind Power and Transmission Networks for Offshore Wind Farms, Glasgow, Scotland, 2006.

[12] DIgSILENT, "DIgSILENT PowerFactory," 14.0.524.2 ed. Gomaringen, Germany, 2011. 